\title{
Investigative Analysis On Hard Turning Process
}

\section{Gaddam Vasikerappa ${ }^{1}$, G. Rajkumar ${ }^{2}$, C. Mohan Naidu ${ }^{3}$}

${ }^{1}$ M.Tech Student, Department of Mechanical Engineering, SKD Engineering College, Gooty, Andhra Pradesh, India

${ }^{2}$ M.Tech, Assistant Professor, Department of Mechanical Engineering, SKD Engineering College, Gooty, Andhra Pradesh, India

${ }^{3}$ M.Tech, Associate Professor, HOD of Mechanical Engineering, SKD Engineering College, Gooty, Andhra Pradesh, India

\section{ABSTRACT}

In the present work, the work piece material taken is chrome-moly alloy steel. This is a hard material having hardness 48 HRC. This alloy steel bears high temperature and high pressure and its tensile strength is high. It is very resistive to corrosion and temperature. For these useful properties it is used in power generation industry and petrochemical industry. Also it is used to make pressure vessels. For machining of work piece the insert chosen is Tic coated carbide insert. Three factors speed, feed and depth of cut were taken at three levels low, medium and high. By the L27 orthogonal design twenty seven runs of experiments were performed. For each run of experiment the time of cut was 2 minutes. The output responses measured were surface roughness, power consumption, chip reduction co-efficient and tool wear (flank wear). All the output responses were analyzed by SN ratio, analysis of variance, and response table. The criteria chosen here is smaller the better and the method applied is Taguchi method.

Keywords : SN Ratio, Analysis of Variance, Response Table, Flank Wear

\section{INTRODUCTION}

Turning is a machining process in which a cutting tool, typically a non-rotary tool bit, describes a helix tool path by moving more or less linearly while the work piece rotates. Usually the term "turning" is reserved for the generation of external surfaces by this cutting action, whereas this same essential cutting action when applied to internal surfaces (that is, holes, of one kind or another) is called "boring". Thus the phrase "turning and boring" categorizes the larger family of (essentially similar) processes known as lathing.

The cutting of faces on the work piece (that is, surfaces perpendicular to its rotating axis), whether with a turning or boring tool, is called "facing", and may be lumped into either category as a subset.

Turning can be done manually, in a traditional form of lathe, which frequently requires continuous supervision by the operator, or by using an automated lathe which does not. Today the most common type of such automation is computer numerical control, better known as CNC.

\section{TURNING OPERATIONS}

Turning specific operations include

\section{Turning}

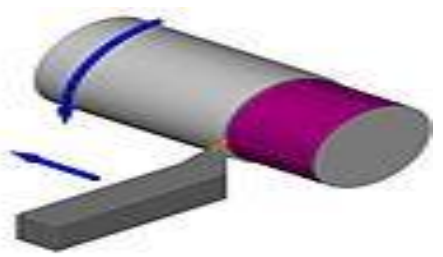




\section{Turning}

The general process of turning involves rotating a part while a single-point cutting tool is moved parallel to the axis of rotation. Turning can be done on the external surface of the part as well as the internal surface (the process known as boring). The starting material is generally a workpiece generated by other processes such as casting, forging, extrusion, or drawing.

\section{Tapered turning}

Tapered turning produces a cylindrical shape that gradually decreases in diameter from one end to the other. This can be achieved a) from the compound slide b) from taper turning attachment c) using a hydraulic copy attachment d) using a C.N.C. lathe e) using a form tool f) by the offsetting of the tailstock this method more suited for shallow tapers.

\section{Spherical generation}

Spherical generation produces a spherical finished surface by turning a form around a fixed axis of revolution. Methods include a) Using hydraulic copy attachment b) C.N.C. (computerized numerically controlled) lathe c) Using a form tool (a rough and ready method) d) Using bed jig (need drawing to explain).

\section{Hard turning}

Hard turning is a type of turning done on materials with a Rockwell C hardness greater than 45 . It is typically performed after the work piece is heat treated.

The process is intended to replace or limit traditional grinding operations. Hard turning, when applied for purely stock removal purposes, competes favorably with rough grinding. However, when it is applied for finishing where form and dimension are critical, grinding is superior. Grinding produces higher dimensional accuracy of roundness and cylindricity. In addition, polished surface finishes of $\mathrm{Rz}=0.3-0.8 \mathrm{z}$ cannot be achieved with hard turning alone. Hard turning is appropriate for parts requiring a roundness accuracy of 0.5-12 micrometers, and/or surface roughness of $\mathrm{Rz} 0.8-7.0$ micrometers. It is used for gears, injection pump components, and hydraulic components, among other applications.

\section{Facing}

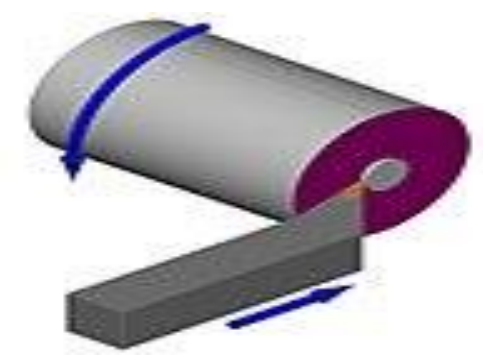

Facing

Facing in the context of turning work involves moving the cutting tool at right angles to the axis of rotation of the rotating work piece. This can be performed by the operation of the cross-slide, if one is fitted, as distinct from the longitudinal feed (turning). It is frequently the first operation performed in the production of the work piece, and often the last-hence the phrase "ending up".

\section{Parting}

This process, also called parting off or cutoff, is used to create deep grooves which will remove a completed or part-complete component from its parent stock.

\section{Grooving}

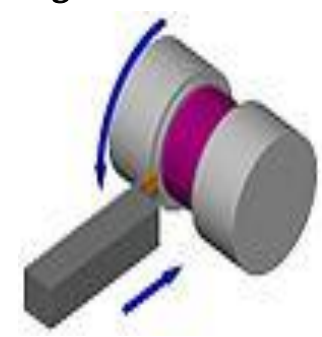

External grooving

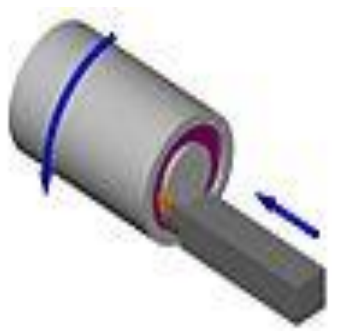

Face grooving
Grooving is like parting, except that grooves are cut to a specific depth instead of severing a 
completed/part-complete component from the stock. Grooving can be performed on internal and external surfaces, as well as on the face of the part (face grooving or trepanning).

\section{BACKGROUND}

Hard machining means machining of parts whose hardness is more than 45HRC but actual hard machining process involves hardness of 58HRC to 68HRC.The work piece materials used in hard machining are hardened alloy steel, tool steels , case hardened steels , nitride irons , hard - chrome coated steels and heat - treated powder metallurgical parts.

\section{1) ADVANTAGES (BENEFITS) OF HARD MACHINING}

1. Complex part contours can be easily machined by this process.

2. Component types can be quickly changed over in this process.

3. In one set - up, many operations can be completed.

4. Metal removal rate is very high.

5. The CNC Lathe which is used for soft turning process can be used for this process.

6. Investment in machine tool is very low.

7. Metal chips produced in the process are environmentally friendly.

8. No coolant is required in many cases.

9. Tool inventory required is small.

\section{2) LIMITATIONS (DRAW BACKS) OF HARD}

\section{MACHINING}

1. The cost of tooling in case of hard machining is higher than grinding.

2. For hard turning the length to diameter (L/D) ratio should be small. For unsupported work pieces it should not be more than 4:1 because long thin parts will induce chatter due to high cutting pressure.

3. For hard machining to be successful, the machine used must be rigid. The degree of hard turning accuracy is known from degree of machine rigidity. If we want to maximize the machine rigidity than we have to minimize overhangs, tool extensions and to eliminate shims and spacers.

4. The main challenge in hard machining is whether or not to use coolants, in some cases where there are interrupted cuts such as gears dry machining is good. Due to shock produced by thermal effect the insert will feel exiting and entering cut and insert will break. In case of continuous cut due to high tool tip temperature softens the area which are machined previously and decreases the value of hardness due to which material is easily cut. But due to dry machining part thermal distortion, handling and in process gauging is difficult so if coolant will be used then water based coolants should be used.

5. Surface finish decreases with increase of tool wear in the range of tool life.

6. In hard machining, a very thin layer of material which is harder than inner material is formed which is known as white layer. With tool wear increase its thickness increases. White layer is commonly formed on bearing steel and makes problem for bearing races which receive high contact stresses. The white layer causes bearing failure.

\section{3) FEATURES IN WHICH HARD MACHINING IS} DIFFERENT FROM CONVENTIONAL MACHINING

1. When work material gets fractured chip in the form of saw tooth is formed. Within the range of shear strain crack is formed at the free surface of the work piece.

2. Because of adiabatic shear segmental chips are formed in materials which are difficult to 
machine and its cross section is similar to sawtoothed chip formed in hard machining but these two chips are not same because they are produced due to different mechanisms.

3. The shear angle in case of hard machining is very small and increases with increase of hardness of work material and do not depend upon tool rake angle but the shear angle in case of traditional machining is large.

4. Radial (thrust) component of the cutting force is greater than tangential (power) component cutting force in case of hard machining. The difference between these two forces increases with increase of flank wear.

5. The tangential (power) component and radial (thrust) component depend upon the tool rake angle. At zero rake angle the components do not increase with hardness of material. At tool rake angle -20 degree, these components reduce with hardness of work material.

6. The chip compression ratio is equal to two in case of hard machining.

7. The radial component and tangential component depend upon flank wear differently. When flank wear increases from zero to $0.2 \mathrm{~mm}$ the radial component increases four fold.

\section{4) FACTORS DISTINGUISHING HARD MACHINING}

To distinguish between hard machining conventional machining differences in energy balance should be analyzed. The formula for balance of energy in metal cutting is given by $\mathrm{P}_{\mathrm{C}}=\mathrm{F}_{\mathrm{c}} \mathrm{V}$

$=$ Ppd + Pfr + Pjf + Pch

Where $F_{C}=$ power(tangential) component of the cutting force.

$\mathrm{V}=$ cutting speed

$\mathrm{Ppd}=$ power consumed due to plastic deformation $\mathrm{Pfr}$ = power used on tool chip interface
$\mathrm{Pjf}=$ power used on tool work piece interface

$\mathrm{P}_{\mathrm{ch}}=$ power used due to formation of new surfaces

The difference in the energy balance in conventional and hard machining of AISI steel 52100 the following conclusions are made.

1. In hard machining power spent on tool work piece surface is greatest but in conventional machining it is opposite.

2. Much power is spent in formation of new surfaces in hard machining.

3. Also power spent in the plastic deformation of layer being removed is much.

\section{5) HARD TURNING}

Hard turning is a process which eliminates the requirements of grinding operation. A proper hard turning process gives surface finish $R_{a} 0.4$ to 0.8 micrometer, roundness about 2-5 micrometer and diameter tolerance +/-3-7micrometre. Hard turning can be performed by that machine which soft turning is done. The starting point of hard turning is the material hardness 47 HRC but regularly hard turning is done on the material having hardness 60HRC and higher. The materials required for hard turning are tool steel, case-hardened steel, bearing steel, Inconel, Hastealloy, stellite and other exotic materials are also falling in the category of hard turning.

\section{THEORITICAL STUDY}

\section{SURFACE ROUGHNESS}

Due to the increased knowledge and constant improvement of the surface textures gives the present machine age a great advancement. Due to the demand of greater strength and bearing loads smoother and harder surfaces are needed. The surface texture has direct contact with the functioning of machine parts, load carrying capacity, tool life, fatigue life, bearing corrosion and wear qualities. Failure due to fatigue 
always occurs at the sharp corners because of stress concentration at that place. Sharp corner is the place where any surface irregularity starts and that part fails earlier.

First order:- This type of irregularities are arising due to inaccuracies in the machine tool itself for example lack of straightness of guide ways on which tool post is moving. Irregularities produced due to deformation of work under the action of cutting forces and the weight of the material are also included in this category.

a) Second order:- This order of irregularities are caused due to vibration of any kind such as chatter marks.

b) Third order:- If the machine is perfect and completely free of vibrations still some irregularities are caused by machining due to characteristics of the process. For example feed mark of cutting tool.

c) Fourth order:- This type of irregularities are arised due to rupture of the material during the separation of the chip.

\section{6) Terms used in surface finish}

Roughness: - This is produced due to irregular structures in the surface roughness which is resulted from the inherent action of production process.

Waviness: - This is produced due to deflection in work piece or machine vibrations produced in machine.

Flaws: - The irregularities which are produced at one place or infrequently in widely varying intervals in a surface are called flaws.

Centre line:-The line about which roughness is measured.

Traversing length: - It is the length of the profile necessary for the evaluation of the surface roughness parameters. The traversing length includes one or more sampling lengths.
Sampling length:- It is the length of profile necessary for the evaluation of the irregularities to be taken into account also known as cut off length.

Mean line of the profile:- It is the line having the form of the geometrical profile and dividing the effective profile so that within the sampling length the sum of squares of the distances between effective points and the mean line is minimum.

Centre line of the profile: - It is the line parallel to the general direction of the profile for which the areas embraced by the profile above and below the line are equal.

Spacing of the irregularities:- It is the mean distance between the more prominent irregularities of the effective profile, within the sampling length.

Different parameters used in measuring surface roughness

Arithmetic average roughness:- $\mathrm{R}_{\mathrm{a}}=1 / L \int_{0}^{L} \bmod (h) d x$ over 2-20 consecutive sampling lengths.

Average peak-to-valley height $\left(\mathbf{R}_{\mathbf{Z}}\right)$ :-This is the average of single peak-to-valley heights from five adjoining sampling lengths.

Depth of surface smoothness:- $\mathrm{R}_{\mathrm{p}}=1 / \mathrm{L} \int_{0}^{L}(\operatorname{Hmax}-H) d x$

Levelling depth $(R \mathbf{u})$ :- Distance between mean line and a parallel line through highest peak.

Mean depth( $(\mathbf{R})$ :- Distance between mean line and a parallel line through the deepest valley.

Maximum peak-to-valley height( $\operatorname{Rmax})$ :-Largest single peak-to-valley heights in five adjoining sampling lengths.

Root mean square roughness: ${ }^{R_{4}}=\sqrt{1 / L f_{0}^{L} h^{2}} d x$

\section{7) Methods of measuring surface roughness}

There are two methods of measuring the finish of machined part. They are 
(i) Surface inspection by comparison methods

(ii) Direct instrument measurements

\section{Surface inspection by comparison}

In comparative methods the surface texture is assessed by observation of the surface. But these methods are not reliable as they can be misleading if comparison is not made with surfaces produced by same techniques. The various methods available under comparison method are
(i) Torch inspection
(ii) Visual inspection
(iii) Scratch inspection
(iv) Microscopic inspection
(v) Surface photographs
(vi) Micro-Interferometer
(vii) Wallace surface dynamometer
(viii) Reflected light intensity

\section{(ii) Direct instrument measurement}

Stylus probe instruments are as follows:- Surface finish of any surface can be measured by this method. In this type measurement electrical principles are used and they are stylus probe type instrument. There are two types of these electrical instruments. Carrier modulating principle is the first type of operation. The movements of the stylus exploring the surface are caused to high frequency carrier current. Second type works on voltage generating principle.

\section{i. Profilometer}

ii. The Tomlinson surface meter

iii. The Taylor-Hobson Talysurf

iv. Stylus

Out of the above four only Taylor-Hobson Talysurf is used in our experiment this to calculate surface roughness.

\section{TOOL WEAR IN TURNING}

A constant cutting force is acting in turning operation and turning is a continuous process. A high temperature is produced at the tool/chip interface because of constant heat derived from shear deformation energy and friction. The principal wear factor in turning is high temperature at the tool rake face. The temperature is around 600 degree for austenitic steels, super alloys or titanium alloys. Tool wear mechanisms in turning are basically four types in turning. They are as follows

\section{Crater wear}

2. Notch wear

3. Flank wear

4. Adhesion

Crater wear: It is a chemical or metallurgical wear. Crater wear is produced because small particles of the tool rake surface diffuse or adhere on fresh chip. Scar like shape is produced on the rake face due to mechanical friction and it is parallel to the major cutting edge. In turning of titanium alloys and low thermal conductivity materials crater wear is produced.

Notch wear: It is a combination of flank wear and rake face wear which occurs just in the point where major cutting edge intersects the work surface. This type of wear is produced in those materials which have a tendency to surface hardening due to mechanical loads. When tool passes rub the fresh machined surface increases hardness of the outer layer. In turning of austenitic stainless steels and nickel-based alloysnotch wear is produced.

Flank wear: This type of wear is produced on the flank face of the tool. Wear land formation is not uniform along major and minor cutting edge of the tool. This type of wear is produced in case of hard materials because there is not any chemical affinity between tool and material. The wear mechanism is due to abrasion in this case.

Adhesion: Welding occurs between the fresh surface of the chip and tool rake face because high pressure and temperature. If materials have metallurgical affinity the there will be better welding and that will produce a thick adhesion layer and tearing of the 
softer rubbing surface at high wear rate. In Aluminium alloys this type of wear is produced in dry conditions. In hard machining this type of wear is not produced.

Wear curve: The following curve shows mean flank wear(VB) along time for various cutting speeds. This wear curve is divided into three regions as given below in fig.

- Initial wear region: In this region the sharp new edge worn rapidly. The wear size $\mathrm{VB}=0.05-0.1$ $\mathrm{mm}$ in this region.

- Steady wear region: In this region wear rate is constant and increases slowly. In this zone $\mathrm{VB}=0.05-0.6 \mathrm{~mm}$ onwards.

- Severe wear region: In this region tool wears in very high rate. When this zone is reached anew tool must be used in place of worn tool or sharpening must be done before tool breakage.

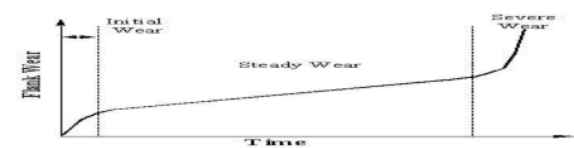

Development of flank wear with respect to time

\section{CUTTING TOOL MATERIALS USED IN CASE OF} HARD MACHINING

During hard machining high temperatures are produced and big mechanical load is there due to speed so cutting tools must withstand these two things. In some cases the temperature in the tool/chip interface reaches around 700 degree centigrade. Severe friction is produced between tool and chip as well as tool and new machined surface. Keeping in mind the above things the cutting tool materials should have the following properties:

- Cutting tool substrate material must be chemically and physically stable at high temperatures.

- Material hardness must withstand high temperatures produced at the chip/tool interface.
- For abrasion and adhesion mechanisms tool material should have a low wear ratio.

- To perform interrupted and intermittent cutting tool material must have enough toughness to avoid fracture.

Starting from the lowest hardness to the highest hardness the tool materials can be classified as follows:-

- High speed steel (H.S.S.)

- Sintered carbide

- Ceramics

- Extra hard materials

High speed steel: These are of high content carbon steels with a high proportion of alloying elements such as tungsten, molybdenum, chromium, vanadium and cobalt. Hardness is about 75 HRC. The T series includes tungsten, the $\mathrm{M}$ series molybdenum. Vanadium produces the hardest carbides and produces super high speed steels. HSS can withstand temperature upto 500 degree centigrade. The HSS produced by power metallurgy process(HSS-PM) possesses a higher content alloying elements and unique properties like higher toughness, higher wear resistance, higher hardness, higher hot hardness.

Sintered carbide: Mixing tungsten carbide micro grains with cobalt at high temperature and pressure sintered carbide tools are produced. These are also known as cemented carbide tools. Tantalum, Titanium, Vanadium carbides are also mixed in small amount. Sintered carbides are described by two main factors. One is the ratio of tungsten carbide and cobalt. Cobalt ranges from 6 to $12 \%$ and it acts as binder. Melting point of Cobalt is 1493 degree centigrade.

Cobalt forms a soluble phase with tungsten carbide grains at 1275 degree centigrade and helps to reduce porosity. Second is the micro grain size. Micro grain size is smaller than 1 micrometer and submicrograin 
are smaller than half micron. The hardness of sintered carbide increases with the reduction in binder content and tungsten carbide grain size. Hardness of sintered carbide ranges from $600 \mathrm{HV}$ to $1200 \mathrm{HV}$. Sintered carbides are manufactured in two forms, integral tools and inserts. Sintered carbides are classified into six groups $\mathrm{M}, \mathrm{P}, \mathrm{K}, \mathrm{N}, \mathrm{S}, \mathrm{H}$. Each scale includes a numerical scale for it. In USA C-x scale is used. $\mathrm{M}$, grade includes the sintered carbides suitable for stainless steel machining. P, includes sintered carbides for low and medium carbon steels and light alloyed steels. $\mathrm{K}$, includes sintered carbides for cast irons and alloyed steels. N, is used for Aluminium alloys, S, for heat resistant alloys and $\mathrm{H}$, for tempered and hardened steels.

For each of the above grades the two digit number 01 to 40 is used, except $\mathrm{P}$, for which 01 to 50 is used. Lower number indicates harder grades and higher number indicates tougher grades. In USA C- 1 to $\mathrm{C}-4$ are general grades for cast iron, $\mathrm{C}-5$ to $\mathrm{C}-8$ are for steel alloys, C-9 to C-11 for high wear applications, C-12 to C-14 for impact cases. The two basic groups of carbides used for machining are tungsten carbide and Titanium carbide.

a) Tungsten carbide: WC particles are bonded together with cobalt matrix to give tungsten carbide composite. By powder metallurgy technique WC particles are bonded together with cobalt in a mixer resulting in cobalt matrix surrounding WC particles and by this process tungsten carbide tools are manufactured. WC is frequently compounded with Titanium and Niobium to impart special properties to the carbide. Steels, Cast irons and abrasive non-ferrous materials are cut by Tungsten carbide tools.

b) Titanium carbide: Tic has higher wear resistance than WC but it is not as tough as WC. Nickel-molybdenum alloy is used as matrix. Steels and cast irons can be machined by TIC.
Ceramics: Ceramics can be used for machining the metals at high cutting speeds and in dry machining conditions because these are very hard and refractory materials which can withstand up to 1500 degree centigrade without chemical decomposition. Ceramic powders are used to mould ceramic materials at pressures $25 \mathrm{MPa}$. Sintering of ceramic materials are done at 1700 degree centigrade. Ceramic tools may be of three types for example alumina tools (Al2O3), Silicon nitride (Si3N4) and sialon which is combination of $\mathrm{Si}, \mathrm{Al}, \mathrm{O}$ and $\mathrm{N}$. Alumina tools contain mixture of titanium, magnesium, chromium, or zirconium oxides distributed into alumna matrix homogenously.

Due to this toughness gets improved. Silicon nitride ceramics have a higher resistance to thermal shock and a higher toughness. Ceramics have a needle like structure embedded in grain boundary which increases fracture toughness. These are applied for roughing cast iron under heavily interrupted cuts. Ceramic tools must be kept hot throughout the operation and shocks on tool edges at tool entrances exits from the work piece must be avoided.

Extra-hard materials: Extra-hard materials include PCD and PCBN. PCD is used for machining abrasive non-ferrous metals, plastics and composites. PCBN is used for machining of hardened tool steels and cast irons.

\section{TAGUCHI METHOD}

The methodology applied in this study is Taguchi method. It is a combination of methodologies by which inherent variability of materials and manufacturing processes has been taken into consideration during design. Controlled and noise both factors are considered in this design. Taguchi design is similar to design of experiment but it conducts the orthogonal experimental combinations which makes the method more effective than fractional factorial design. Taguchi method uses special design of orthogonal arrays to 
study the entire patameter space with small no of experiments. Taguchi uses the loss function for the measurement of the performance characteristics deviating from the desired value. The value of loss function is converted to $\mathrm{S} / \mathrm{N}$ ratio. There are three types of $\mathrm{S} / \mathrm{N}$ ratios e.g lower-the-better, Higher-thebetter, Nominal-is- best. The formula for three types of $\mathrm{S} / \mathrm{N}$ ratio is given below.

Nominal-is-the-best: $\mathrm{S} / \mathrm{N}_{\mathrm{T}}=1 \log \left(\frac{\bar{y}}{s_{y}^{2}}\right)$

Larger-is-the-better (maximize): $\mathrm{S} / \mathrm{N}_{\mathrm{L}}=-10 \log \left(\frac{1}{n} \sum_{i=1}^{n} \frac{1}{y_{i}^{2}}\right)$

Smaller-is-the-better (minimize): $\mathrm{S} / \mathrm{N}_{\mathrm{s}}=-10 \log \left(\frac{1}{n} \sum_{i=1}^{n} y_{i}^{2}\right)$

Where $\bar{y}$ is the average of observed data and $s_{y}^{2}$ is the variance of $\mathrm{y}, \mathrm{n}$ is the no. of observations and $\mathrm{y}$ is the observed data. $\mathrm{S} / \mathrm{N}$ ratio is always expressed in decibel. If the objective is to reduce the variability around a specific target then $\mathrm{S} / \mathrm{NT}$ is used. If the system is optimized when response is as large as possible $\mathrm{S} / \mathrm{NL}$ is used. If the system is optimized when the response is optimized as small as possible $\mathrm{S} / \mathrm{N}_{\mathrm{S}}$ is used. The goal of this research is to produce minimum surface roughness, minimum power consumption, minimum chip reduction co-efficient, and minimum tool wear in turning operation. The larger value of $\mathrm{S} / \mathrm{N}$ ratio means the better performance characteristics so the optimal level of the process parameters is the level with the highest $\mathrm{S} / \mathrm{N}$ ratio. A statistical analysis of variance is performed to see statistically significant process parameters.

\section{EXPERIMENTAL DETAILS}

\section{WORK PIECE MATERIAL}

The work piece is chrome-moly alloy which is prepared at cast profile private limited, Kalunga. Its length is 600 $\mathrm{mm}$ and diameter is $50 \mathrm{~mm}$. It is heat treated to make its hardness upto 48 HRCThe photograph of work piece material and chemical composition of the CR$\mathrm{MO}$ alloy is given below in fig.

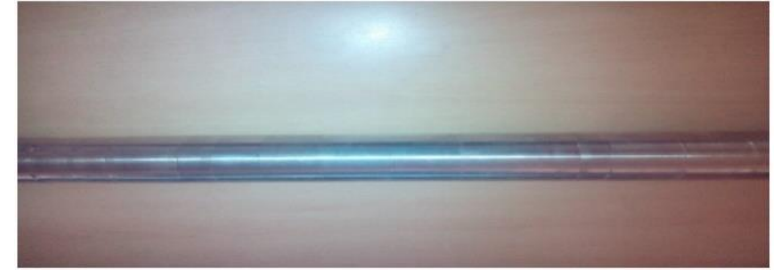

Work piece material (Cr-Mo round bar)

Dimension of Cr-Mo alloy:

Length of bar $=600 \mathrm{~mm}$

Diameter of bar $=50 \mathrm{~mm}$

Hardness of material $=48$ HRC

\section{CUTTING INSERTS}

Cutting inserts used in this experiment are four in number. Each insert has eight edges so for 27 experiment all eight edges of first three are used and three edges of last insert is used. The specification of insert is SNMG 120408. The inserts are Tic coated carbide inserts. The photographs of all inserts used in experiment, their specification and geometry are given below in fig(a), (b), (c), (d):

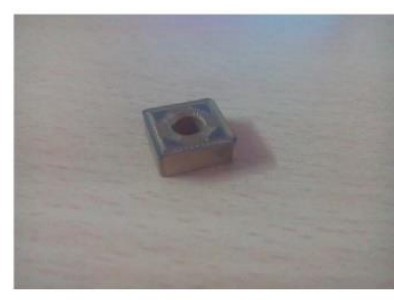

Insert-1

(A)

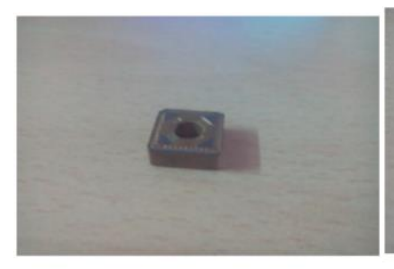

Insert-3

(C)

\section{Specification of inserts}

SNMG120408

S:-Insert shape (square)

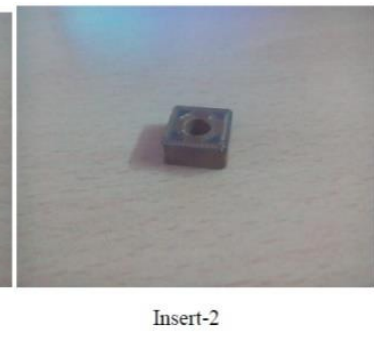

(B)

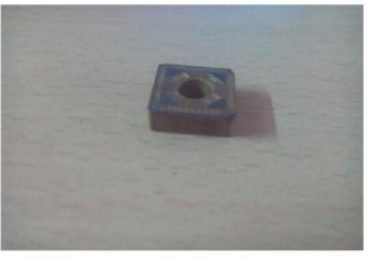

Insert-4

(D)

Cutting inserts 
$\mathrm{N}$ :-Clearance angle (0 degree)

M:-Tolerances

G:-Form of top surface

$12 \mathrm{~mm}$ :-Cutting edge length

$04 \mathrm{~mm}$ :-Insert thickness

$08 \mathrm{~mm}$ :-Corner radius

Geometry of inserts:-

Inclination

angle $=-6$ degree

Orthogonal rake

angle $=-6$ degree

Orthogonal clearance angle $=6$ degree

Auxiliary cutting edge angle $=15$ degree

Principal cutting edge angle $=75$ degree

Nose radius $=$

$0.8 \mathrm{~mm}$

\section{TOOL HOLDER}

The tool holder used for the experiment is PSBNR2525M12. Its photograph and specification is given below in fig.

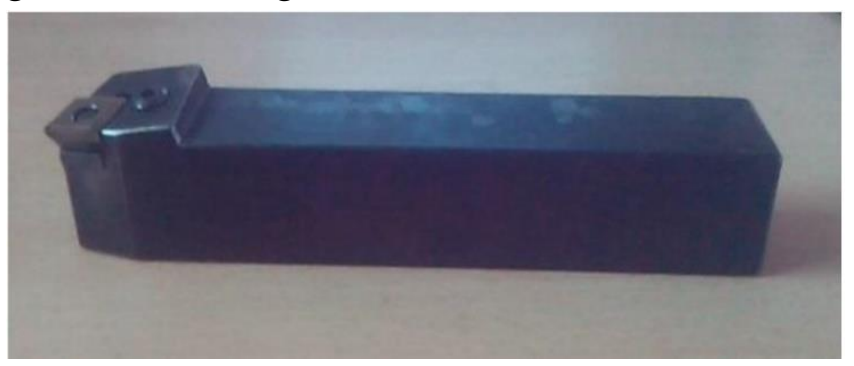

Tool holder (PSBNR2525M12)

\section{Specification of tool holder}

P:-Clamping method (Retained via bore) S:-Insert shape (square)

B:-Style (75 degree)

$\mathrm{N}$ :-Clearance angle (0 degree)

R:-Cutting direction (right handed) $25 \mathrm{~mm}$ :-Shank height

25 mm:-Shank width

M:-Tool length150 mm
12 mm:-Cutting edge length

\section{LATHE MACHINE USED FOR EXPERIMENT}

The type of machine used for hard turning Cr-Mo alloy is conventional lathe machine with high rigidity. Cutting tests were carried out under dry cutting environment. Dry machining has been considered as the machining of the future due to concern regarding the safety of the environment. The experimental setup is given in fig.

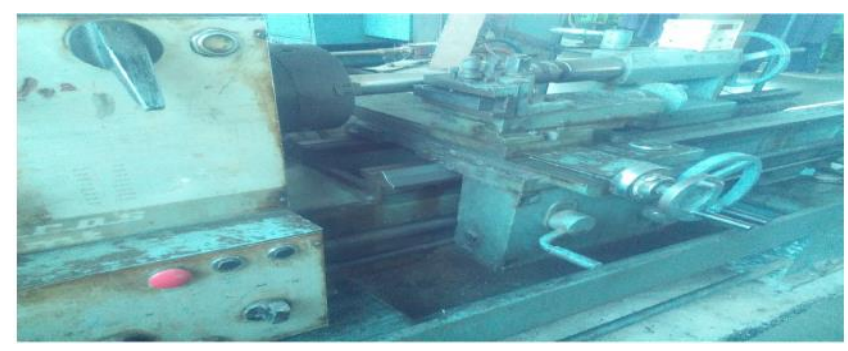

Lathe machine with work piece

\section{SURFACE ROUGHNESS TESTER USED IN EXPERIMENT}

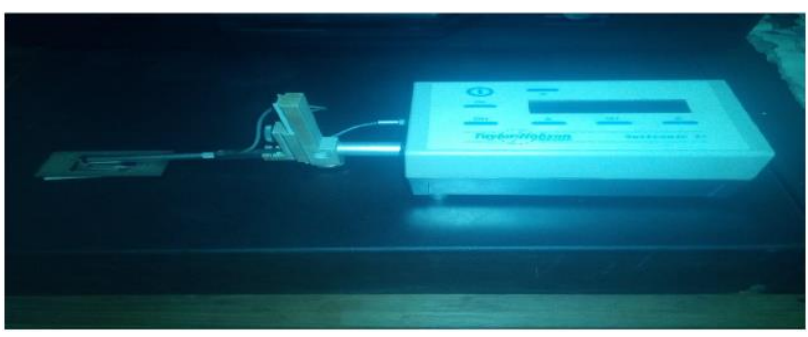

Taylor-Hobson (sutronic 3+)

\section{Specification}

Traverse speed: $1 \mathrm{~mm} / \mathrm{second}$

Measurement unit: Metric/Inch

Cut-off values: $0.25 \mathrm{~mm}, 0.80 \mathrm{~mm}, 2.5 \mathrm{~mm}$ (0.01 in,

0.03 in, 0.1 in)

Parameters: Ra, Rq, Rz(DIN), Ry and Sm

Calculation time: Less than reversal time or 2 second whichever is longer

\section{MICROMETRE USED TO CALCULATE CHIP THICKNESS}

The micrometre used to calculate chip thickness is given below in fig with its specification. 


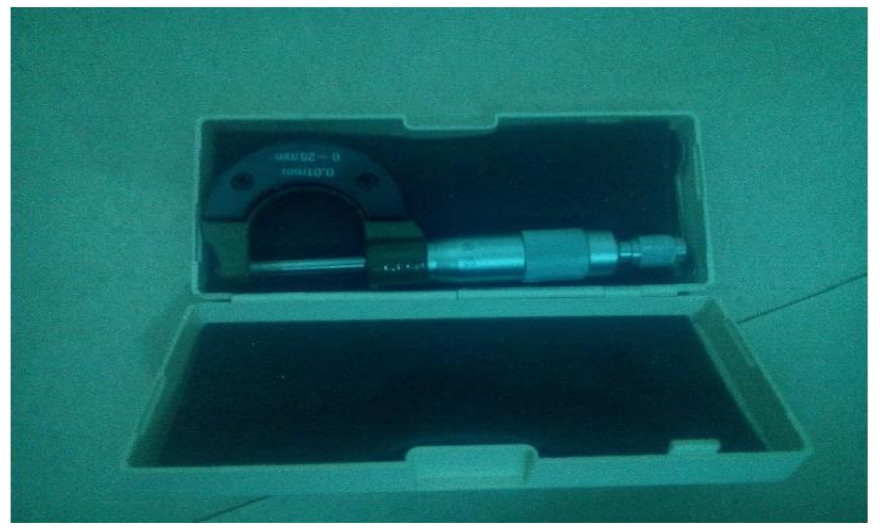

Micrometre

\section{Specification}

Least count: $0.01 \mathrm{~mm}$

Range: 0-25 mm

\section{EXPERIMENTAL PROCEDURE}

The rough work piece of chrome-moly alloy bought from cast profile Ltd, kalunga is first turned to clear the rough skin using uncoated carbide insert. The final diameter of the work piece is made $50 \mathrm{~mm}$. The two ends of the work piece are faced and centring is done using carbide centre drill. The final length of the work piece was made $600 \mathrm{~mm}$. The purpose of this experiment is to find the effect of speed, feed and depth of cut on output responses like surface roughness, power consumption, chip reduction coefficient and tool wear.

The chip reduction co-efficient can be given by formula below.

Chip reduction co-efficient = Chip thickness / Undeformed chip thickness

\section{Undeformed chip thickness $=\mathrm{f} \operatorname{sinKr}$}

Where $\mathrm{f}$ is the feed and $\mathrm{kr}$ is the principal cutting edge. The table for power and chip reduction coefficient was shown in table.

Table 1. The levels of speed, feed and depth of cut

\begin{tabular}{|c|c|c|c|}
\hline Levels & Speed in rpm & $\begin{array}{c}\text { Feed in } \\
\mathrm{mm} / \mathrm{re} \\
\mathrm{v}\end{array}$ & $\begin{array}{c}\text { D.O.C in } \\
\mathrm{mm}\end{array}$ \\
\hline Low & 250 & 0.1 & 0.3 \\
\hline Medium & 420 & 0.13 & 0.5 \\
\hline High & 710 & 0.15 & 1.0 \\
\hline
\end{tabular}

Table 2. power and chip reduction co-efficient

\begin{tabular}{|c|c|c|c|c|c|c|c|c|c|}
\hline $\begin{array}{l}\text { Run. } \\
\text { no }\end{array}$ & $\begin{array}{l}\text { Speed } \\
\text { In } \\
\text { r.p.m }\end{array}$ & $\begin{array}{l}\text { Feed } \\
\text { In } \\
\mathrm{mm} / \mathrm{rev}\end{array}$ & $\begin{array}{l}\text { d.o.c } \\
\text { in } \\
\mathrm{mm}\end{array}$ & $\begin{array}{l}\text { V } \\
\text { In } \\
\text { volt }\end{array}$ & $\begin{array}{l}\text { I } \\
\text { in } \\
\text { amp }\end{array}$ & P.F. & $\begin{array}{l}\mathrm{P}=\frac{\mathrm{VI}(\mathrm{PF})}{1000} \\
\text { in k.w. }\end{array}$ & $\begin{array}{l}\text { C.T. } \\
\text { In } \\
\text { Mm }\end{array}$ & $\begin{array}{l}\xi=\mathrm{C} \cdot \mathrm{T} / \mathrm{U} . \mathrm{C} \\
. \mathrm{T}\end{array}$ \\
\hline 1 & 250 & 0.1 & 0.3 & 410 & 4.7 & 0.21 & 0.405 & 0.11 & 1.138 \\
\hline 2 & 250 & 0.1 & 0.5 & 409.3 & 4.81 & 0.31 & 0.610 & 0.20 & 2.070 \\
\hline 3 & 250 & 0.1 & 1.0 & 400.8 & 4.42 & 0.28 & 0.496 & 0.29 & 3.002 \\
\hline 4 & 250 & 0.13 & 0.3 & 411.4 & 4.72 & 0.20 & 0.388 & 0.08 & 0.637 \\
\hline 5 & 250 & 0.13 & 0.5 & 406.6 & 4.69 & 0.25 & 0.476 & 0.17 & 1.353 \\
\hline 6 & 250 & 0.13 & 1.0 & 401.5 & 4.53 & 0.30 & 0.545 & 0.13 & 1.035 \\
\hline 7 & 250 & 0.15 & 0.3 & 416 & 4.98 & 0.21 & 0.435 & 0.14 & 0.966 \\
\hline 8 & 250 & 0.15 & 0.5 & 407.6 & 4.72 & 0.25 & 0.480 & 0.27 & 1.863 \\
\hline 9 & 250 & 0.15 & 1.0 & 410.2 & 4.81 & 0.30 & 0.592 & 0.31 & 2.139 \\
\hline
\end{tabular}




\begin{tabular}{|l|l|l|l|l|l|l|l|l|l|}
\hline 10 & 420 & 0.1 & 0.3 & 415.6 & 4.81 & 0.25 & 0.500 & 0.14 & 1.449 \\
\hline 11 & 420 & 0.1 & 0.5 & 408.6 & 4.70 & 0.27 & 0.518 & 0.14 & 1.449 \\
\hline 12 & 420 & 0.1 & 1.0 & 400.8 & 4.70 & 0.42 & 0.791 & 0.22 & 2.277 \\
\hline 13 & 420 & 0.13 & 0.3 & 415.7 & 4.92 & 0.24 & 0.491 & 0.07 & 0.577 \\
\hline 14 & 420 & 0.13 & 0.5 & 407.6 & 4.67 & 0.27 & 0.514 & 0.16 & 1.274 \\
\hline 15 & 420 & 0.13 & 1.0 & 403.1 & 4.78 & 0.43 & 0.830 & 0.26 & 2.070 \\
\hline 16 & 420 & 0.15 & 0.3 & 418.5 & 4.87 & 0.24 & 0.489 & 0.08 & 0.552 \\
\hline 17 & 420 & 0.15 & 0.5 & 408.6 & 4.78 & 0.32 & 0.624 & 0.20 & 1.380 \\
\hline 18 & 420 & 0.15 & 1.0 & 402.6 & 4.75 & 0.43 & 0.822 & 0.21 & 1.449 \\
\hline 19 & 710 & 0.1 & 0.3 & 417.0 & 5.06 & 0.31 & 0.654 & 0.09 & 0.724 \\
\hline 20 & 710 & 0.1 & 0.5 & 407.8 & 4.92 & 0.38 & 0.762 & 0.04 & 0.414 \\
\hline 21 & 710 & 0.1 & 1.0 & 401.5 & 5.01 & 0.58 & 1.166 & 0.11 & 1.138 \\
\hline 22 & 710 & 0.13 & 0.3 & 416.0 & 4.94 & 0.32 & 0.662 & 0.05 & 0.398 \\
\hline 23 & 710 & 0.13 & 0.5 & 410.6 & 4.98 & 0.40 & 0.818 & 0.12 & 0.955 \\
\hline 24 & 710 & 0.13 & 1.0 & 400.2 & 5.45 & 0.61 & 1.330 & 0.19 & 1.513 \\
\hline 25 & 710 & 0.15 & 0.3 & 412.3 & 4.96 & 0.41 & 0.838 & 0.15 & 1.035 \\
\hline 26 & 710 & 0.15 & 0.5 & 407.8 & 4.78 & 0.39 & 0.760 & 0.09 & 0.621 \\
\hline 27 & 710 & 0.15 & 1.0 & 402.3 & 5.02 & 0.49 & 0.989 & 0.22 & 1.518 \\
\hline
\end{tabular}

In the above table P.F means power factor, C.T means chip thickness, U.C.T means undeformed chip thickness, $\xi$ stands for chip reduction co-efficient. $\mathrm{P}$ stands for power.

\section{FINAL EXPERIMENTAL TABLE}

Final experimental table is given below. This table contains three input variables speed, feed and depth of cut. The levels of were in R.P.M. and they were 250, 420 and 710 R.P.M. These speeds were converted into $\mathrm{m} / \mathrm{min}$ using formula $\pi D N / 1000$ where $\mathrm{D}$ is the diameter of work piece and $\mathrm{N}$ is the R.P.M. of Lathe machine. The outputs are surface roughness in micron, power in k.w. chip reduction co-efficient and tool wear in $\mathrm{mm}$.

Table 3. Final experimental table

\begin{tabular}{|l|l|l|l|l|l|l|l|}
\hline Run.no & $\begin{array}{l}\text { Speed in } \\
\mathrm{m} / \mathrm{min}\end{array}$ & $\begin{array}{l}\text { Feed in } \\
\mathrm{mm} / \mathrm{rev}\end{array}$ & $\begin{array}{l}\text { d.o.c. in } \\
\mathrm{mm}\end{array}$ & $\begin{array}{l}\text { S.R in } \\
\text { micron }\end{array}$ & $\begin{array}{l}\text { Power in } \\
\mathrm{k.w}\end{array}$ & $\begin{array}{l}\text { Chip } \\
\text { reduction } \\
\text { co- } \\
\text { efficient }\end{array}$ & $\begin{array}{l}\text { Tool } \\
\text { wear in } \\
\mathrm{mm}\end{array}$ \\
\hline
\end{tabular}




\begin{tabular}{|c|c|c|c|c|c|c|c|}
\hline 1 & 39.275 & 0.1 & 0.3 & 1.10 & 0.405 & 1.138 & 1.26 \\
\hline 2 & 39.275 & 0.1 & 0.5 & 1.44 & 0.610 & 2.070 & 0.96 \\
\hline 3 & 39.275 & 0.1 & 1.0 & 0.04 & 0.496 & 3.002 & 0.88 \\
\hline 4 & 39.275 & 0.13 & 0.3 & 1.56 & 0.388 & 0.637 & 1.62 \\
\hline 5 & 39.275 & 0.13 & 0.5 & 1.66 & 0.476 & 1.353 & 0.675 \\
\hline 6 & 39.275 & 0.13 & 1.0 & 1.42 & 0.545 & 1.035 & 0.657 \\
\hline 7 & 39.275 & 0.15 & 0.3 & 1.02 & 0.435 & 0.966 & 1.96 \\
\hline 8 & 39.275 & 0.15 & 0.5 & 1.82 & 0.480 & 1.863 & 0.813 \\
\hline 9 & 39.275 & 0.15 & 1.0 & 1.50 & 0.592 & 2.139 & 0.965 \\
\hline 10 & 65.982 & 0.1 & 0.3 & 0.88 & 0.500 & 1.449 & 0.624 \\
\hline 11 & 65.982 & 0.1 & 0.5 & 1.64 & 0.518 & 1.449 & 0.58 \\
\hline 12 & 65.982 & 0.1 & 1.0 & 0.80 & 0.791 & 2.277 & 0.923 \\
\hline 13 & 65.982 & 0.13 & 0.3 & 0.72 & 0.491 & 0.557 & 0.363 \\
\hline 14 & 65.982 & 0.13 & 0.5 & 1.70 & 0.514 & 1.274 & 0.798 \\
\hline 15 & 65.982 & 0.13 & 1.0 & 1.16 & 0.830 & 2.070 & 0.827 \\
\hline 16 & 65.982 & 0.15 & 0.3 & 0.84 & 0.489 & 0.552 & 0.522 \\
\hline 17 & 65.982 & 0.15 & 0.5 & 1.20 & 0.624 & 1.380 & 0.457 \\
\hline 18 & 65.982 & 0.15 & 1.0 & 1.14 & 0.822 & 1.449 & 0.572 \\
\hline 19 & 65.982 & 0.1 & 0.3 & 0.84 & 0.654 & 0.724 & 1.204 \\
\hline 20 & 111.541 & 0.1 & 0.5 & 1.32 & 0.792 & 0.414 & 0.147 \\
\hline 21 & 111.541 & 0.1 & 1.0 & 1.18 & 1.166 & 1.138 & 0.16 \\
\hline 22 & 111.541 & 0.13 & 0.3 & 1.2 & 0.662 & 0.398 & 1.588 \\
\hline 23 & 111.541 & 0.13 & 0.5 & 1.32 & 0.818 & 0.955 & 1.465 \\
\hline 24 & 111.541 & 0.13 & 1.0 & 2.50 & 1.330 & 1.513 & 0.916 \\
\hline 25 & 111.541 & 0.15 & 0.3 & 1.92 & 0.838 & 1.035 & 1.787 \\
\hline 26 & 111.541 & 0.15 & 0.5 & 3.08 & 0.760 & 0.621 & 0.967 \\
\hline 27 & 111.541 & 0.15 & 1.0 & 1.50 & 0.989 & 1.518 & 0.601 \\
\hline
\end{tabular}

\section{CHIP COLLECTED DURING EXPERIMENT}

The chips were collected during all 27 experiments and their thickness were measured using micrometre shown in Fig-4.6. The chip reduction co-efficient was calculated for each chip using the formula Chip reduction co-efficient = Chip thickness / Undeformed chip thickness

Undeformed chip thickness $=f \sin K_{r}$
Where $\mathrm{f}$ is the feed and $\mathrm{kr}$ is the principal cutting edge of the insert. The photographs of all the chips were shown below in fig(i) up to (xxvii).

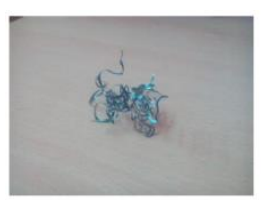

[i]

[ii]

[iii] 


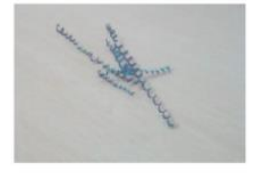

[iv]

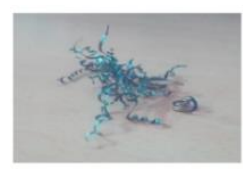

[vii]

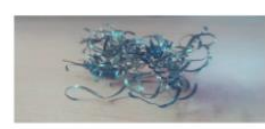

[x]

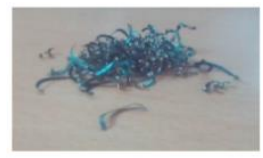

[xiii]

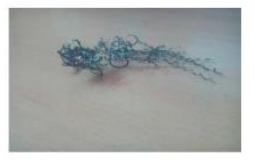

[xvi]

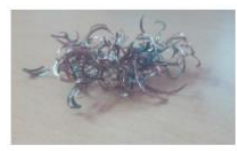

[xix]

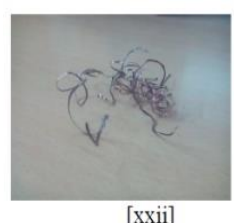

[xxii]

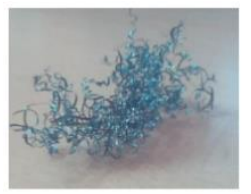

[xxv]

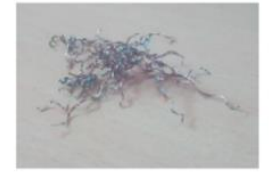

[v]

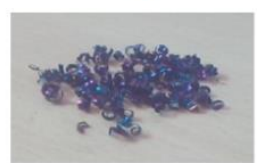

[viii]

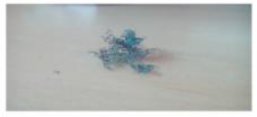

[xi]

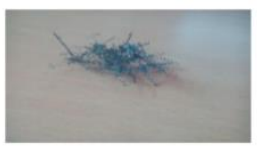

[xiv]

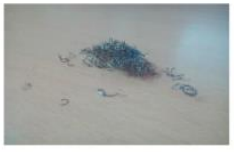

[xvii]

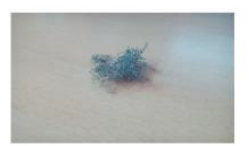

[xx]

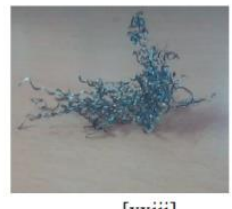

[xxiii]

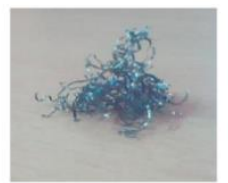

[xxvi]

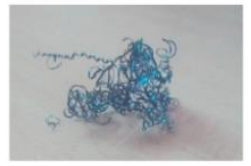

[vi]

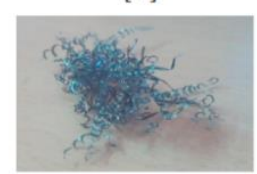

[ix]

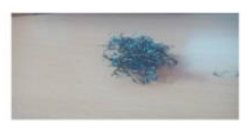

[xii]

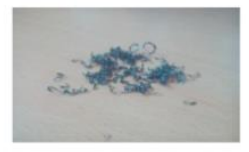

[xv]

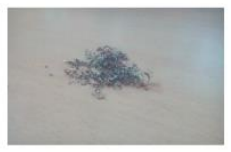

[xviii]

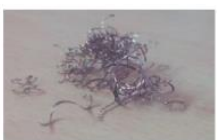

[xxi]

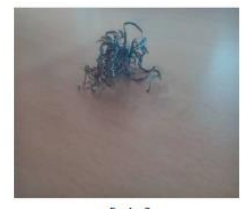

[xiv]

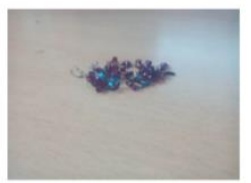

[xxvii]

Photographs of all the chips

\subsection{PHOTOGRAPHS OF TOOL WEARS}

The photographs of 27 tool wears of edges of inserts taken by stereo zoom microscope are given in Fig-(i) up to (xxvii).
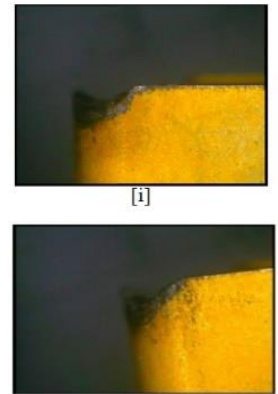

[iv]

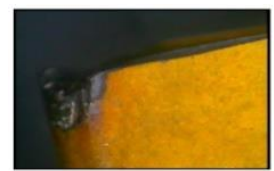

[vii]

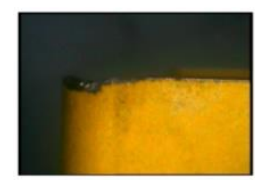

[xiii]

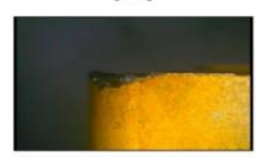

[xvi]

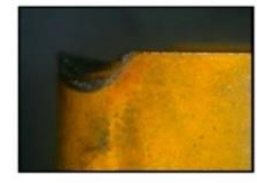

[Xix]

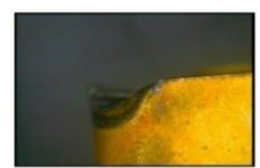

[xxii]

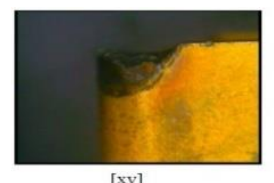

[xv]

Photographs of tool wears

\section{RESULTS AND DISCUSSION}

\section{MAIN EFFECT PLOTS FOR SURFACE ROUGHNESS}

The Fig-(a), (b), (c) shows the main effects for surface roughness that means the graphs of speed vs. mean of $\mathrm{S} / \mathrm{N}$ ratios of surface roughness, feed vs. mean of $\mathrm{S} / \mathrm{N}$ ratios of surface roughness, depth of cut vs. mean of 
$\mathrm{S} / \mathrm{N}$ ratios of surface roughness for lower is better. As the speed increases the mean of $\mathrm{S} / \mathrm{N}$ ratios decreases that means good surface finish is obtained with increase in speed. From the graph(b) it is clear that as the feed increases surface roughness decreases that means increase in feed also gives good surface finish. From the graph (c) it is clear that as the depth of cut increases first surface roughness decreases upto some value and then increases. From three graphs the slope of feed vs. mean of $\mathrm{S} / \mathrm{N}$ ratio graph is largest, depth of cut vs. mean of $\mathrm{S} / \mathrm{N}$ ratio graph possesses second largest slope so surface roughness is significantly affected by feed and depth of cut but cutting speed has not significant effect on surface roughness.

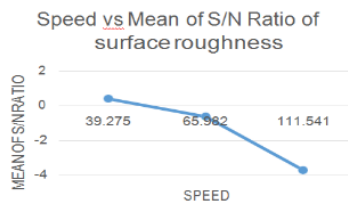

[a]

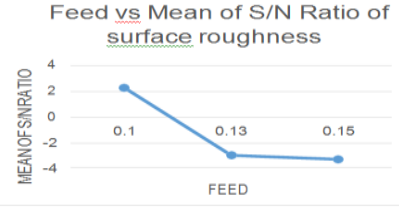

[b]

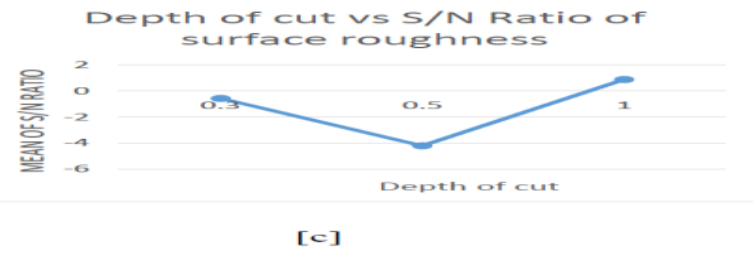

Main effect plots for surface roughness

\section{MAIN EFFECT DIAGRAM OF POWER CONSUMPTION}

Figure-(a), (b) and (c) given below shows the main effect plots for power consumption in machining for lower is better. Figure-(a) shows the graph of speed vs. mean of $\mathrm{S} / \mathrm{N}$ ratio of power consumption. From the graph it is clear that as the speed increases the power consumption decreases. Figure-(b) shows feed vs. mean of $\mathrm{S} / \mathrm{N}$ ratio for power consumption. The graph shows that as the feed increases the power consumption decreases. Figure(c) shows depth of cut vs. mean of $\mathrm{S} / \mathrm{N}$ ratio of power. The graph shows that as the depth of cut increases the power consumption decreases. Out of three graphs the slope of cutting speed vs. mean of $\mathrm{S} / \mathrm{N}$ ratio has largest slope and depth of cut vs. mean of $\mathrm{S} / \mathrm{N}$ ratio

has the second largest slope so cutting speed and depth of cut significantly affect the power consumption but feed has no significant effect on power consumption.

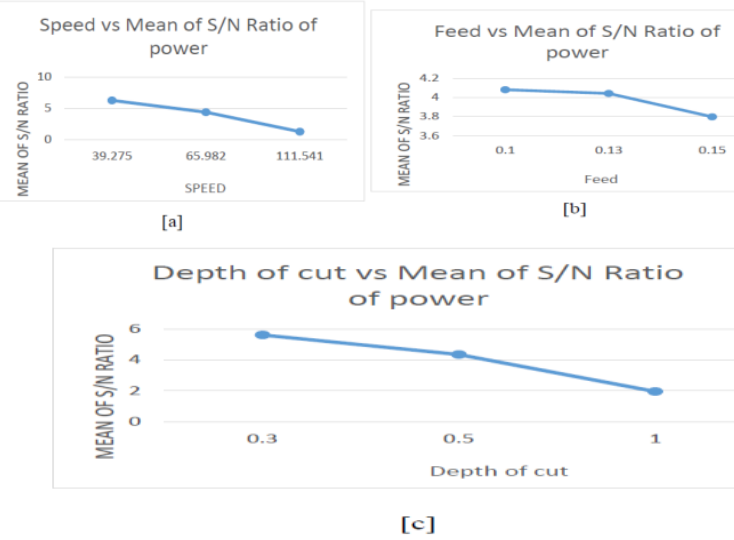

Main effect diagram of power consumption MAIN EFFECT PLOT OF CHIP REDUCTION COEFFICIENT

The figure-(a), (b), (c) given below shows the main effects of chip reduction co-efficient. The figure (a) shows the graph of speed vs. mean of $\mathrm{S} / \mathrm{N}$ ratio of chip reduction co-efficient for lower is better. As the speed increases the mean of $\mathrm{S} / \mathrm{N}$ ratio increases that means chip reduction co-efficient becomes more. The graph in (b) shows the graph between feed vs. mean of $\mathrm{S} / \mathrm{N}$ ratio of chip reduction co-efficient. As the feed increases the mean of $\mathrm{S} / \mathrm{N}$ ratio increases first and then decreases. The graph in (c) shows the graph between depth of cut vs. mean of chip reduction coefficient. From this graph it is clear that as the depth of cut increases the mean of $\mathrm{S} / \mathrm{N}$ ratio decreases. Out three graphs the (c) graph has the largest slope, (a) graph has second largest slope so depth of cut and cutting speed have the significant effect on chi reduction co-efficient but feed has not any significant effect.

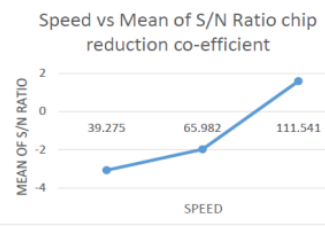

[a]

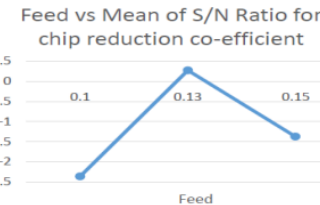

[b] 


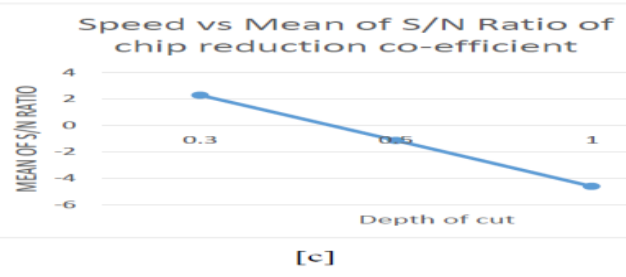

Main effect plot of chip reduction co-efficient

\section{MAIN EFFECT DIAGRAM OF TOOL WEAR}

The figures given in (a), (b), (c) shows the main effect diagrams of tool wear for lower are better. The (a) shows speed vs. mean of $\mathrm{S} / \mathrm{N}$ ratio of tool wear. The graph shows that as the speed increases the tool wear increases first after some speed tool wear decreases. Out of three graphs the slope of (a) is largest, slope of (c) is second largest so tool wear is affected by speed and depth of cut significantly but feed has not any significant effect on tool wear.

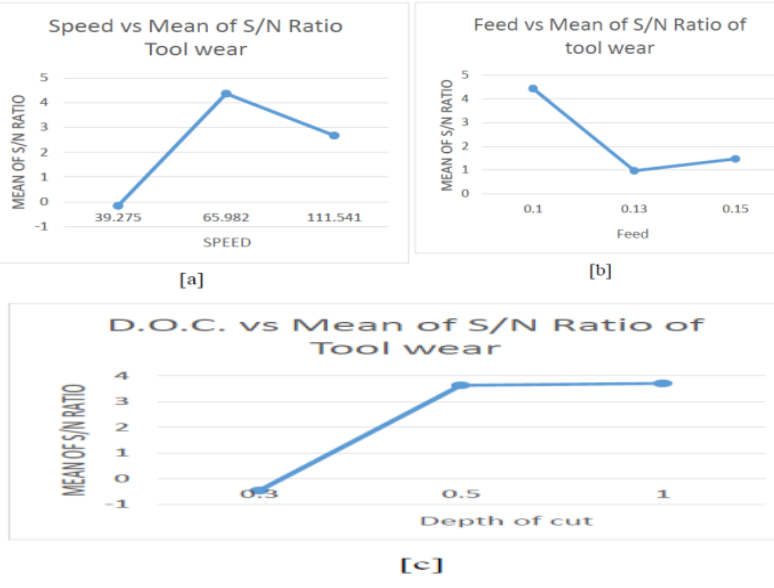

Main effect diagram of tool wear

\section{ANOVA AND RESPONSE TABLE FOR SURFACE ROUGHNESS}

The anova table for surface roughness shows DF, SS, MS, F- value, P- value. From F-statistics it is clear that feed and depth of cut are significant. Cutting speed has not any significant effect on surface roughness. The response table shows that the rank of feed is one and rank of depth of cut is two that means feed and depth of cut has significant effect on surface roughness. Table- shows the Anova table for surface roughness and Table- shows the response table for surface roughness.

Table-(ANOVA for surface roughness)

\begin{tabular}{|c|c|c|c|c|c|c|}
\hline Source & DF & Seq. SS & Adj SS & Adj MS & F & P \\
\hline $\mathrm{V}$ & 2 & 82.41 & 82.41 & 41.20 & 1.20 & 0.349 \\
\hline $\mathrm{F}$ & 2 & 171.56 & 171.56 & 85.75 & 2.51 & 0.143 \\
\hline $\mathrm{D}$ & 2 & 123.87 & 123.87 & 61.93 & 1.81 & 0.225 \\
\hline $\mathrm{V}^{*} \mathrm{f}$ & 4 & 134.48 & 134.48 & 33.62 & 0.98 & 0.469 \\
\hline $\mathrm{V}^{*} \mathrm{~d}$ & 4 & 147.50 & 147.50 & 36.87 & 1.08 & 0.428 \\
\hline $\mathrm{f}^{*} \mathrm{~d}$ & 4 & 178.82 & 178.82 & 44.71 & 1.31 & 0.346 \\
\hline $\begin{array}{c}\text { Residual } \\
\text { error }\end{array}$ & 8 & 273.91 & 273.91 & 34.24 & & \\
\hline Total & 26 & 1112.55 & & & & \\
\hline
\end{tabular}

Table-(Response table)

\begin{tabular}{|c|c|c|c|}
\hline Level & Speed & Feed & Depth of cut \\
\hline 1 & 0.4176 & 2.2645 & -0.5688 \\
\hline 2 & -0.6112 & -2.9232 & -4.2060 \\
\hline 3 & -3.6942 & -3.2290 & 0.8871 \\
\hline Delta & 4.1117 & 5.4936 & 5.0931 \\
\hline Rank & 3 & 1 & 2 \\
\hline
\end{tabular}

ANOVA AND RESPONSE TABLE FOR POWER CONSUMPTION

The table- shows the anova table for power consumption and table- shows the response table for power consumption. The ANOVA table shows DF, SS, MS, F-value, $\mathrm{P}$-value. The F- statistics shows that cutting speed and depth of cut are significant. Also pvalues for speed and depth of cut are less than 0.05. The delta statistics in response table shows the rank of cutting speed is one and depth of cut is two that means cutting speed and depth of cut are significant.

Table-(ANOVA for power consumption)

\begin{tabular}{|l|l|l|l|l|l|l|}
\hline Source & $\begin{array}{l}\text { D } \\
\text { F }\end{array}$ & Seq. SS & $\begin{array}{l}\text { Adj. } \\
\text { SS }\end{array}$ & $\begin{array}{l}\text { Adj. } \\
\text { MS }\end{array}$ & F & P \\
\hline V & 2 & 113.444 & $\begin{array}{l}113.44 \\
4\end{array}$ & $\begin{array}{l}56.722 \\
1\end{array}$ & 54.04 & 0.000 \\
\hline F & 2 & 0.419 & 0.419 & 0.2096 & 0.20 & 0.823 \\
\hline D & 2 & 62.341 & 62.341 & $\begin{array}{l}31.170 \\
5\end{array}$ & 29.70 & 0.000 \\
\hline $\mathrm{V}^{*} \mathrm{f}$ & 4 & 1.471 & 1.471 & 0.3676 & 0.35 & 0.837 \\
\hline $\mathrm{V}^{*} \mathrm{~d}$ & 4 & 9.184 & 9.184 & 2.2961 & 2.19 & 0.161 \\
\hline
\end{tabular}




\begin{tabular}{|l|l|l|l|l|l|l|}
\hline$f^{*} d$ & 4 & 2.865 & 2.865 & 0.7162 & 0.68 & 0.624 \\
\hline $\begin{array}{l}\text { Residual } \\
\text { error }\end{array}$ & 8 & 8.397 & 8.397 & 1.0496 & & \\
\hline Total & 26 & 198.121 & & & & \\
\hline
\end{tabular}

\begin{tabular}{|l|l|l|l|l|l|l|}
\hline $\begin{array}{l}\text { Residual } \\
\text { error }\end{array}$ & 8 & 47.81 & 47.81 & 5.976 & & \\
\hline Total & 26 & $\begin{array}{l}553.8 \\
8\end{array}$ & & & & \\
\hline
\end{tabular}

Table-(Response table for $\mathrm{S} / \mathrm{N}$ ratio)

\begin{tabular}{|l|l|l|l|}
\hline Level & Cutting speed & Feed rate & Depth of cut \\
\hline 1 & -3.0784 & -2.3598 & 2.2918 \\
\hline 2 & -1.9764 & 0.2731 & -1.1415 \\
\hline 3 & 1.5958 & -1.3724 & -4.6094 \\
\hline Delta & 4.6742 & 2.6329 & 6.9012 \\
\hline Rank & 2 & 3 & 1 \\
\hline
\end{tabular}

ANOVA AND RESPONSE TABLE FOR TOOL WEAR

The tables shows the ANOVA and response table for $\mathrm{S} / \mathrm{N}$ ratios of tool wear. The table shows the ANOVA table for tool wear which contains DF, SS, MS, F, $\mathrm{P}$ value.

The F- statistics as well as $\mathrm{p}$-value shows that response table for $\mathrm{S} / \mathrm{N}$ ratio of chip reduction coefficient. The ANOVA for chip reduction co-efficient shows DF, SS, MS, F, P value. The P-value for depth of cut and cutting speed are less than 0.05 so they significant. Table shows the response table for chip reduction co-efficient. The delta statistics shows the rank of feed as one and rank of cutting speed as two means they are significant.

Table-(ANOVA for chip reduction co-efficient)

\begin{tabular}{|l|l|l|l|l|l|l|}
\hline Source & DF & Seq.SS & $\begin{array}{l}\text { Adj. } \\
\text { SS }\end{array}$ & $\begin{array}{l}\text { Adj. } \\
\text { MS }\end{array}$ & F & P \\
\hline V & 2 & $\begin{array}{l}107.4 \\
7\end{array}$ & $\begin{array}{l}107.4 \\
7\end{array}$ & $\begin{array}{l}53.73 \\
4\end{array}$ & 8.99 & .009 \\
\hline F & 2 & 31.84 & 31.84 & $\begin{array}{l}15.92 \\
2\end{array}$ & 2.66 & .130 \\
\hline D & 2 & 214.3 & 214.3 & $\begin{array}{l}107.1 \\
60\end{array}$ & 17.93 & .001 \\
\hline $\mathrm{V}^{*} \mathrm{f}$ & 4 & 69.37 & 69.37 & $\begin{array}{l}17.34 \\
2\end{array}$ & 2.90 & .093 \\
\hline $\mathrm{V}^{*} \mathrm{~d}$ & 4 & 45.24 & 45.24 & 11.31 & 1.89 & .205 \\
& & & & 1 & & \\
\hline $\mathrm{f}^{*} \mathrm{~d}$ & 4 & 37.83 & 37.83 & 9.457 & 1.58 & .269 \\
\hline
\end{tabular}

Table-(ANOVA for tool wear)

\begin{tabular}{|l|l|l|l|l|l|l|}
\hline Source & DF & Seq.SS & Adj.SS & $\begin{array}{l}\text { Adj.M } \\
\text { S }\end{array}$ & F & P \\
\hline V & 2 & 93.73 & 93.73 & 46.866 & 4.31 & 0.054 \\
\hline F & 2 & 63.29 & 63.29 & 31.644 & 2.91 & 0.112 \\
\hline D & 2 & 102.52 & 102.52 & 51.262 & 4.71 & 0.044 \\
\hline $\mathrm{V}^{*} \mathrm{f}$ & 4 & 223.90 & 223.90 & 55.974 & 5.15 & 0.024 \\
\hline $\mathrm{V}^{*} \mathrm{~d}$ & 4 & 170.03 & 170.03 & 42.508 & 3.91 & 0.048 \\
\hline $\mathrm{f}^{*} \mathrm{~d}$ & 4 & 34.56 & 34.56 & 8.64 & 0.79 & 0.561 \\
\hline $\begin{array}{l}\text { Residual } \\
\text { error }\end{array}$ & 8 & 87.00 & 87.00 & 10.875 & & \\
\hline Total & 26 & 775.04 & & & & \\
\hline \multicolumn{7}{|c|}{ Table-(Response table) } \\
\hline
\end{tabular}

\begin{tabular}{|l|l|l|l|}
\hline Level & Cutting speed & Feed rate & Depth of cut \\
\hline 1 & -0.1564 & 4.4378 & -0.4633 \\
\hline 2 & 4.3595 & 0.9680 & 3.6320 \\
\hline 3 & 2.6732 & 1.4705 & 3.7076 \\
\hline Delta & 4.5159 & 3.4697 & 4.1710 \\
\hline Rank & 1 & 3 & 2 \\
\hline
\end{tabular}

v. CONCLUSION AND FUTURE WORK 


\section{CONCLUSION}

Based on experimental results presented and discussed, the following conclusions are drawn on the effect of cutting speed, feed and depth of cut on the performance of Tic coated carbide tool when machining Cr-Mo alloy.

- The study of Main effect plots of surface roughness indicates that as speed increases mean of $\mathrm{SN}$ ratio decreases that means good surface finish is obtained with increase in speed. As the feed increase mean of $\mathrm{SN}$ ratio decreases that means good surface finish is obtained with increase in feed. As the depth of cut increases from $0.3 \mathrm{~mm}$ to $0.5 \mathrm{~mm}$ surface roughness decreases but when depth of cut increase from $0.5 \mathrm{~mm}$ to $1 \mathrm{~mm}$ surface roughness increases.

- The slope of feed vs. mean of SN ratio is largest, depth of cut vs. mean of $\mathrm{SN}$ ratio has the second largest slope so feed and depth of cut affect the surface roughness significantly which is clear from F-statistics of ANOVA and rank of response table. So feed and depth of cut are dominant factors for surface roughness.

- As the speed increases SN ratio for power decreases. As the feed and depth of cut increases also SN ratio for power decreases that means less power is consumed for increase of speed, feed and depth of cut.

- Cutting speed and depth of cut are significant factors in case of power.

- As the speed increases mean of SN ratio increases that means chip reduction co- efficient becomes more when speed increases. As feed increases from 0.1 to 0.13 chip reduction co-efficient increases and from 0.13 to 0.15 chip reduction co-efficient decreases. As the depth of cut increases chip reduction co-efficient decreases.
- The depth of cut and speed affect significantly chip reduction co-efficient.

- When speed increases from $39.275 \mathrm{~m} / \mathrm{min}$ to $65.982 \mathrm{~m} / \mathrm{min}$ tool wear increases and from $65.982 \mathrm{~m} / \mathrm{min}$ to $111.541 \mathrm{~m} / \mathrm{min}$ tool wear decreases. When feed increases from 0.1 to 0.13 $\mathrm{mm} / \mathrm{rev}$ tool wear decreases rapidly but from $0.13 \mathrm{~mm} / \mathrm{rev}$ to $0.15 \mathrm{~mm} / \mathrm{rev}$ tool wear increases slowly. When depth of cut increases from $0.3 \mathrm{~mm}$ to $0.5 \mathrm{~mm}$ tool wear increases, from $0.5 \mathrm{~mm} 1.0$ $\mathrm{mm}$ it remains constant.

- Tool wear is affected significantly by cutting speed and d.o.c.

\section{FUTURE WORK}

- In the present work chrome-moly alloy steel is used for machining process so in future work other hard materials like Inconel-718 can be used for machining by the same process varying speed, feed and depth of cut in L-27 orthogonal array design and taguchi method may be used for analysis.

- Some other cutting inserts like ceramic or CBN may be used for cutting instead of coated carbide insert and the experiment may be repeated insame way the result may be compared with previous result.

- Rsm may be used for analysis process instead of Taguchi method.

\section{REFERENCES}

[1]. Dilbag Singh and P.Venkateswara Rao "A surface roughness prediction model for hard turning process" int. J. Adv. Manuf. Technol(2007) 32 : 1115-1124

[2]. Tugrul Ozel , Tsu-Kong Hsu , Erol Zeren “ Effects of Cutting edge geometry, work piece hardness, feed rate and cutting speed on surface roughness and forces in finish turning of 
hardened AISI H13 steel" int. J. Adv. Manuf.Technol(2005) 25 : 262-269.

Gaddam Vasikerappa, G. Rajkumar, C. Mohan Naidu, "Investigative Analysis On Hard Turning Process", International Journal of Scientific Research in Science and Technology (IJSRST), Online ISSN : 2395-602X, Print ISSN : 2395-6011, Volume 6 Issue 3, pp. 166-184, May-June 2019. Available at doi : https://doi.org/10.32628/IJSRST196333 Journal URL : http://ijsrst.com/IJSRST196333 hard turning process of Inconel using response surface surface methodology" Int. J. of emerging technology and advanced engineering, ISSN 2250-2459, volume2, Issue 10, October 2012.

[5]. K. Adersh Kumar et all "Optimisation of surface roughness in face turning operation in machining of EN-8" International Journal of Engineering Science and emerging technology Vol 2, issue-4, 807-812, July-Aug 2012.

[6]. S.B.Salvi et all "Analysis of of surface roughness in hard turning by using Taguchi method" international Journal of Engineering science and technology vol5, No-2 Feb 2013.

[7]. F. Puh et all " optimisation of hard turning process parameters with PCBN tool based on the Taguchi method" Technical Gazette 19, 2(2012), 415-419.

[8]. Ali Riza Motorcu " The optimisation of machining parameters using the Taguchi method for surface roughness of AISI 8660 hardened alloy steel" Journal of mechanical Engineering 56(2010)6, 391-401.

[9]. R. Ramanujam et all " Taguchi multi machining characteristics optimisation in turning of $\mathrm{Al}-15$ $\mathrm{SiCp}$ composites using desirability function analysis" Journal of studies of manufacturing vol-1-2010/Iss2-3 pp120-125.

\section{Cite this article as :}

